\title{
The N.P.L. Primary Standard of Mutual Inductance.
}

UNDER the heading "British Scientific Gift to Japan," the Times recently gave a brief account of a ceremony some fuller details of which may be of interest to readers of NATURE. An absolute standard of mutual inductance was constructed at the National Physical Laboratory in 1907-8 from the designs of Mr. Albert Campbell. The standard was described by Mr. Campbell in 1912, and the value of the coefficient of mutual inductance as found by calculation was given by him as $10017 \cdot 83$ microhenries.

In the early part of $1914, \mathrm{Dr}$. Giebe, of the Reichsanstalt, visited the National Physical Laboratory in order to make an inter-comparison of various standards. The paraffin wax was dissolved off the standard inductance and the coils remeasured. Some slight variations from the original dimensions were observed, and the value of the mutual inductance coefficient when recalculated was found to be 10017.78 microhenries. The coils were not rewaxed.

In 1913 a similar standard, ordered by the Japanese Government, was under construction by Mr. R. W. Paul. This was sent to the Laboratory to be wound and measured with the view of the calculation of its coefficient. The work was delayed by the War, and in 1920 the grooves to hold the wire were recut in the Engineering Department and the standard completed and sent to Japan. It had only just arrived when it was destroyed by the earthquake of 1923. Soon afterwards the Japanese Government placed an order for a new standard. It was then suggested, and the suggestion was welcomed by the Lord President of the Council, Lord Balfour, that the new standard should be constructed at the National Physical Laboratory, and presented by the Lord President to the Japanese Government as a token of sympathy for the losses sustained by the earthquake ; shortly in the Collected Researches of the N.P.L. in

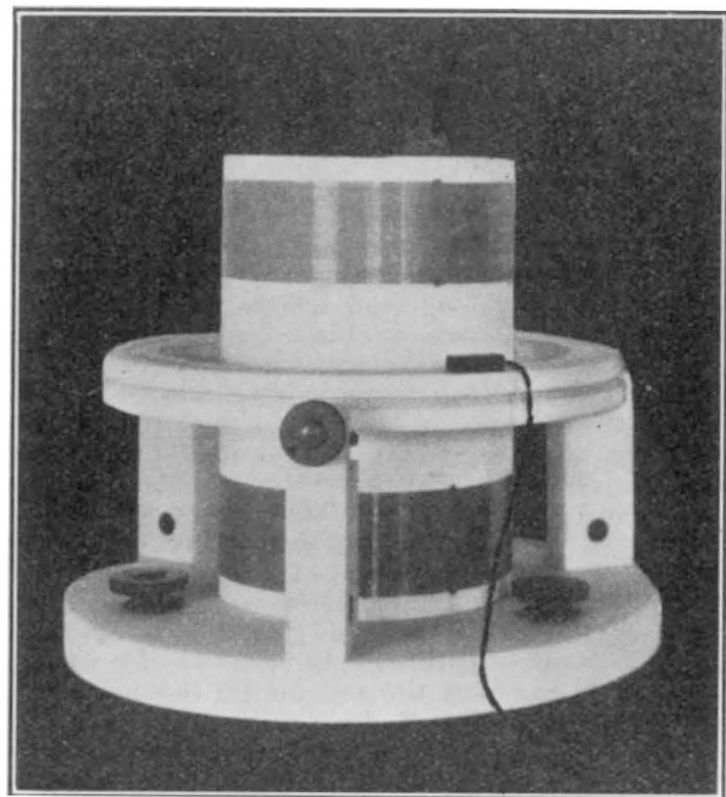

FIG. 1.-Photograph of the Japanese standard mutual inductance, consisting of the inner marble cylinder upon which are the upper and lower single layer primary windings and the outer ring-shaped secondary winding in the channel turned in the ring. The ring is supported on levelling and centring screws attached to the three marble pillars fixed to the base.

a paper by Messrs. Dye and Hartshorn of the Electricity Department of the Laboratory. Fig. 1 is a reproduction of a photograph of the standard. The interest for physicists, however, lies in the fact that its construction has enabled a very careful comparison to be made of the values of the N.P.L. standard since 1914 . The recent results are given in the accompanying table taken from the paper in which the method of comparison is described.

It thus appears that the value of the N.P.L. standard in terms of the new Japanese standard of 1927 is $10017 \cdot 86$ microhenries. In 1921 its value was found by Dr. Dye by comparison with

Mean Value of N.P.L. Standard at $15^{\circ}$ C., $10017 \cdot 86 \mu H$.

this standard is the scientific gift referred to in the Times notice.

A full description of the standard will appear the first Japanese standard to be 10017.83 microhenries. As already stated, its calculated value found in 1914 was $10017 \cdot 78$ microhenries.

\section{Insulin and Synthalin.}

'TO elucidate the chemical constitution of a compound of the nature of insulin, two main lines of approach may be followed; methods may be devised for the isolation of the substance in a state of chemical purity, preferably, if possible, in crystalline form, or the problem may be tackled from the opposite direction, by the synthesis of bodies possessing an insulin-like action, one of which may ultimately be found to be identical with insulin itself. In the follow ing account, brief reference is made to certain of the investigations recently carried out with the view of determining the properties and constitution of insulin.

No. 3039, VoL. 121]
Purification of Insulin : Crystalline Insulin.

In a series of publications, Abel and his collaborators have described methods by means of which solutions of insulin may be made to yield crystals of the active principle. The original method was first described by J. J. Abel in the Proc. Nat. Acad. Sci., vol. 12, p. 132 ; 1926, and involved the use of a purified insulin as a starting-point. To obtain this purified insulin, material of a unitage of about $10-15$ units per mgm. was dissolved in weak acetic acid and precipitated by means of pyridine, the whole process being repeated a number of times: by this means, 35-40 per cent. of 
inactive matter was removed. The material was then extracted in 90 per cent. phenol, the insulin passing into solution, from which it was precipitated by the addition of a large excess of water. The pyridine precipitation in acetic acid solution was then repeated several times, but with a sodium chloride precipitation between the first and second pyridine treatment. The material thus obtained contained 40 units or more per mgm., and was used as the starting-point for preparing crystalline insulin (J.J. Abel and E. M. K. Geiling, Jour. Pharmacol. and Exper. Therap., vol. 25, p. 423 ; 1925).

To a solution of the purified material in acetic acid was added an acidified solution of brucine, by means of which impurities were precipitated. By the addition of pyridine to the clear solution of insulin, the compound was precipitated, largely in a crystalline form, and could be recrystallised by the same means or by dissolving in disodium hydrogen phosphate, adding acetic acid to slight permanent turbidity and setting aside for crystallisation to take place. The crystals obtained were doubly refracting, and belonged to the rhombohedral division of the hexagonal system.

More recently Abel and his collaborators have described a simpler method of obtaining crystals (J. J. Abel, E. M. K. Geiling, C. A. Rouiller, F. K. Bell, and O. Wintersteiner, Jour. Pharmacol. and Exper. Therap., vol. 31, p. 65; 1927). The brucine method was applied directly to material of a unitage of 13 per mgm., and the use of the tedious phenol purification was found to be unnecessary. The material now used gave only a slight precipitate on the addition of the acidified brucine solution, but the addition of pyridine brought down the impurities, together with some of the insulin, provided the reaction was kept well to the acid side of the isoelectric point of the latter. The addition of ammonia to the clear filtrate now brought down crystals, or more usually, they appeared on setting aside to crystallise. The crystals were either rhombohedral and doubly refractive or rhombic dodecahedrons. Tested against the international standard of insulin, the crystalline material showed a unitage of 40 per mgm., and the activity was unchanged on recrystallisation.

Before discussing the chemical properties of the purified material, reference may be made to the work of Dodds and his collaborators (F. Dickens, E. C. Dodds, W. Lawson, and N. F. Maclagan, Biochem. Jour., vol. 21 , p. $560 ; 1927$ ). By entirely different methods from those used by Abel, these workers have succeeded in obtaining an insulin of a unitage of about sixty to the milligram, but they were unable to crystallise their product, using Abel's first method. The steps in the purification were as follows: the insulin, in aqueous solution, was precipitated by the addition of trichloracetic acid to 2 per cent., leaving some of the impurities in solution. The precipitate was dissolved in dilute hydrochloric acid and the potency again precipitated, this time by means of one-third saturation with sodium chloride. The precipitate was again dissolved, in slightly acid water at $p \mathbf{H} 4 \cdot 0$, and an oxalate-oxalic acid mixture of similar reaction added. After standing, the precipitate was centrifuged off, re-dissolved in dilute acid, precipitated as the picrate, and regenerated as the hydrochloride by Dudley's process, which consists in precipitating the hydrochloride from an alcoholic hydrochloric acid solution of the picrate by means of acetone. The purest material was prepared by the use of five oxalate precipitations.

Examination of the chemical properties of the products obtained by these two groups of workers shows that they are of protein nature, thus confirming the conclusions of other investigators. The biuret, Millon's, Pauly's and ninhydrin tests are positive and the tests for tryptophane negative: Molisch's test is also negative. The nitrogen content is about 15 per cent. or somewhat less. Abel suggests the formula $\mathrm{C}_{45} \mathrm{H}_{69} \mathrm{O}_{14} \mathrm{~N}_{11} \mathrm{~S}$. Dodds finds that the arginine, histidine, and especially the lysine fractions are lower in the more purified specimens of his material. The results obtained agree in general with those published by other workers, although there are discrepancies as regards the percentages of the various fractions found on hydrolysis, and in some cases also as to the presence or absence of a particular amino-acid.

Abel has raised the question as to the relationship between the sulphur of the molecule and the physiological activity. He found that boiling the insulin with $N / 10$ sodium carbonate for a short time resulted in loss of potency together with a change in the condition of a portion of the sulphur, such that subsequent treatment with dilute acid led to the liberation of hydrogen sulphide. His experiments suggested that the amount of this 'labile' sulphur present was directly proportional to the potency of the particular sample under examination, the proportion of both total and 'labile' sulphur increasing with increase in potency. About one-third of the sulphur of the molecule appears to be liberated by the dilute alkali in the case of the crystalline preparation. Dodds, however, states that there is no relationship between the sulphur content and the physiological activity, the former being the same in the purest as in relatively impure material. Whether the sulphur in the molecule plays a dominant rôle in relation to the physiological activity, must, then, be left to future work to decide.

The investigations into the chemistry of insulin appear to indicate that it is either itself of the nature of a protein or, as extracted from the pancreas, is always associated with protein material. The fact that products of varying physiological activity can be obtained seems to suggest that the insulin molecule is of a simpler nature than that of any of the compounds hitherto prepared, but is associated with protein material of varying amount and composition, depending upon the particular processes of extraction and purification adopted.

\section{SYNTHALIN.}

The synthesis of certain compounds with an insulin-like action has been described by Frank, Nothmann, and Wagner, one of which, 'synthalin,' has been subjected to extensive clinical trial in cases of diabetes mellitus. The starting-point of this work was the well-known observation that guanidine and its compounds produce, on injection into animals, symptoms resembling tetany in human beings, and even convulsions. The authors found that a dose of $0.3 \mathrm{gm}$. per $\mathrm{kgm}$. body weight, injected subcutaneously into a fasting rabbit, produces convulsions, accompanied by a fall in the blood sugar to 0.035-0.05 per cent. (E. Frank, Naturwissenschaften, vol. 15, p. 213 ; 1927): the administration of sugar or adrenalin can postpone the onset of the hypoglycæmia, given with the guanidine; but once the convulsions have commenced, sugar cannot relieve them. Smaller doses producing no symptoms also cause no fall in blood sugar. Methyl and dimethylguanidine produce convulsions independently of the blood sugar level : the authors therefore turned to a different type of guanidine compound, namely, agmatine, which was first extracted from herring-sperm by Kossel, but can now be prepared synthetically by a process devised by Heyn. Agmatine is amino-butyleneguanidine, and has the formula

$$
\mathrm{HN}=\mathrm{C}\left\langle\frac{\mathrm{NH}_{2}}{\mathrm{NH}} \cdot \mathrm{CH}_{2} \cdot \mathrm{CH}_{2} \cdot \mathrm{CH}_{2} \cdot \mathrm{CH}_{2} \mathrm{NH}_{2}\right. \text {. }
$$


In doses of 0.08 to $0.1 \mathrm{gm}$. per $\mathrm{kgm}$. body-weight, this compound produces a fall in the blood-sugar of 30 per cent. without any obnoxious symptoms : larger doses cause a primary hyperglycæmia, followed by a fall in the blood-sugar and convulsions. The next higher homologue of agmatine, amino-pentyleneguanidine, has a more powerful hypoglycæmic action than the former compound : $0.2 \mathrm{gm}$. per kgm. bodyweight is a convulsive dose, and the symptoms are similar to those produced by insulin, which was not the case with the other compounds investigated. Further, both substances resemble insulin in that the symptoms can be relieved by administering glucose.

Synthalin is closely related to the last two guanidine derivatives, being a diguanidyl derivative of a long chain aliphatic hydrocarbon, but the exact constitution has not yet been published. The toxic effects have been still further dissociated from the hypoglycæmic, doses as low as $0.003 \mathrm{gm}$. per kgm. body-weight producing a definite decrease in the blood-sugar. In applying these results to cases of human diabetes, Frank found that 20-25 mgm. constituted a suitable dose, and that up to $150 \mathrm{mgm}$. could be given in the course of four days. Such a dosage resulted in the utilisation of $40-50 \mathrm{gm}$. of glucose, which would otherwise have been excreted in the urine. If $125 \mathrm{mgm}$. cause the utilisation of $160 \mathrm{gm}$. of glucose in four days, $1 \mathrm{mgm}$. is equivalent to $1.24 \mathrm{gm}$. glucose, or, roughly, to one unit of insulin. Weight for weight, synthalin is therefore considerably less potent in causing a fall in the blood-sugar than the best samples of insulin.

The use of synthalin has in its favour the facts that it can exert its action after oral administration, and that this action, although slower in onset than that of insulin, is much more prolonged : to its disadvantage is the fact that unpleasant symptoms may be produced by it in many patients. The probable mode of action of the drug throws some light on the origin of these symptoms. Workers at the National Institute for Medical Research in London have found that synthalin only produces a decided fall in the blood-sugar in the normal animal in doses which also exert a definitely toxic action on the liver (Lancet, vol. 2 , p. 517 ; 1927). This effect on the liver presumably results in a depression of the new formation of glucose which occurs in that organ, and also explains in part the unpleasant symptoms of nausea, anorexia, etc., frequently encountered in patients taking the drug: these symptoms have been found by Continental observers to be mitigated by the administration of a bile salt derivative, sodium dehydrocholate, to stimulate bile secretion, during the period of action of the synthalin : the toxic effect of the latter on the liver is believed to be counteracted by the simultaneous increase in the activity of the organ.
Apart from its action on the liver, synthalin also accelerates the disappearance of glucose from the circulation in the eviscerated spinal preparation, although the sugar vanishing is not laid down as glycogen in the muscles as is the case with insulin : moreover, large toxic doses of synthalin are necessary to demonstrate this effect. It therefore appears that the two main actions of insulin, depression of new formation of glucose in the liver and accelerated metabolism of sugar present in the blood, are represented in the effect of synthalin, but the fate of the sugar disappearing, which, in the case of insulin action, is partly laid down in the muscles as glycogen and partly burnt to carbon dioxide and water, is not absolutely similar in the two cases.

The clinical usefulness of the compound appears then to depend on how far its insulin-like action can be dissociated from its toxic effects : and this seems to occur to a different degree in different people. In Great Britain, the Medical Research Council has set on foot clinical investigations in a number of different centres, preliminary reports of which have recently been published (Lancet, vol. 2, p. 517; 1927): the same journal also contains a paper by E. G. B. Calvert on the treatment of diabetes by the drug (ibid., p. 649). The results of these investigations show conclusively that synthalin is not a complete substitute for insulin. In certain patients, roughly one-third of the cases so far treated, it exerts a definitely toxic effect, the symptoms suggesting intestinal irritation, although a hepatic element may also be present. In a certain number it appears to be without action, but in others it enables the dosage of insulin to be reduced, although very rarely can its use be abandoned altogether. It has more effect in reducing the glycosuria than in reducing the blood-sugar.

The difficulties of estimating the value of synthalin, or that of any similar therapeutic agent, are considerable: thus, in a case in which synthalin has exerted a favourable influence, the patient may remain well, after withdrawal of the drug, on simple dieting alone; or if symptoms of gastro-intestinal irritation supervene, the accompanying loss of appetite, by reducing the food intake, may suffice to reduce the glycosuria and ameliorate some of the symptoms of the disease. Finally, since synthalin has a toxic action on the liver, it is possible that apparently good results may be due to a mild degree of this toxic action, in which case only time can disclose its real value even in the cases which appear to react successfully to it at the present moment.

Synthalin, then, is not a substitute for insulin: its real usefulness lies. rather in the encouragement its discovery brings to the further investigation of synthetic compounds having an insulin-like action.

\section{The Control of Plant Diseases.}

"Be ye ashamed, oh ye husbandmen; howl, oh ye vinedressers, for the wheat and for the barley; because the harvest of the field is perished. I have smitten you with blasting and mildew."-JoEL i. 11 and AMos iv. 9. TN opening the discussion between Sections $K$ and $\mathrm{M}$ on the control of plant diseases, at the Leeds meeting of the British Association, Mrs. N. L. Alcock chose the above text, and passing lightly over the superstitions of the past regarding disease, she turned to the problem of control as seen to-day by the pathologist and agriculturalist. From the practical point of view, the first full recognition of the importance of plant diseases came with the epidemic of American gooseberry mildew. In 1905, Prof. Salmon, of Wye Agricultural College, while Ireland alone of the British Isles was definitely affected by the disease, gave a clear warning of the need of legislative control of both American gooseberry mildew and of potato wart disease. In another direction the warning was spread in 1909 by Prof. Sommerville in his references to the white pine blister rust, Cronartium ribicola, which he stated was still unknown in America, though it was to be feared that the day was not far distant when its footing in North America would be secured. To-day the losses in America due to this disease are credibly reckoned as enormous.

Neither the spread of American gooseberry mildew in Britain, however, nor the ravages in American

No. 3039 , VoL. 121] 